\title{
A 229-year dendroclimatic-inferred record of forest fire activity for the Boreal Shield of Canada
}

\author{
Martin P. Girardin ${ }^{\mathrm{A}, \mathrm{C}, \mathrm{F}}$, Yves Bergeron ${ }^{\mathrm{B}}$, Jacques C. Tardif ${ }^{\mathrm{C}}$, Sylvie Gauthier ${ }^{\mathrm{A}}$, \\ Mike D. Flannigan ${ }^{\mathrm{D}}$ and Manfred Mudelsee ${ }^{\mathrm{E}}$

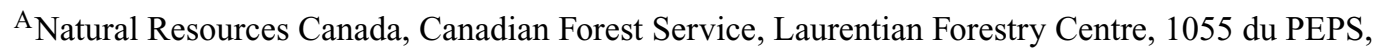 \\ PO Box 10380, Stn. Sainte-Foy, QC G1V 4C7, Canada. \\ ${ }^{\mathrm{B}}$ Groupe de recherche en écologie forestière inter-universitaire (GREFI), Université du Quebec \\ à Montréal, CP 8888, Succ. Centre-Ville, Montréal, QC H3C 3P8, Canada. \\ ${ }^{\mathrm{C}}$ Center for Forest Interdisciplinary Research (C-FIR), University of Winnipeg, 515 Avenue Portage, \\ Winnipeg, MB R3B 2E9, Canada. \\ ${ }^{D}$ Natural Resources Canada, Canadian Forest Service, Great Lakes Forestry Centre, \\ 1219 Queen Street-East, Sault Ste. Marie, ON P6A 2E5, Canada. \\ ${ }^{\mathrm{E}}$ Institute of Meteorology, University of Leipzig, Stephanstrasse 3, 04103 Leipzig, Germany, \\ and Climate Risk Analysis, Wasserweg 2, 06114 Halle, Germany. \\ ${ }^{\mathrm{F}}$ Corresponding author. Email: martin.girardin@rncan.gc.ca
}

\begin{abstract}
Six independent tree-ring reconstructions of summer drought were calibrated against instrumental fire data to develop a 229-year dendroclimatic-inferred record of fire activity (annual area burned and fire occurrence) on the Boreal Shield, Canada. As a means of validating the statistical reconstructions of the fire activity, a comparison was made with a stand age distribution derived from a regional time-since-last-fire map for an area located at the transition between the mixedwood and coniferous boreal forests of south-western Quebec. Calibration statistics indicated that $31 \%$ of the area burned variance and $45 \%$ of the fire occurrence variance could be accounted for by the six drought reconstructions. The verification statistics indicated a tendency for the statistical reconstructions of the fire activity to reproduce with confidence both high and relatively low frequency variations in fire. Episodes of succeeding years with important fire activity were estimated for 1789-1796, 1820-1823, 1837-1841, 1862-1866, 1906-1912, 1919-1922, 1933-1938, and 1974-1977. Also estimated were periods of reduced forest fire activity, particularly in the occurrence rate of extreme fire years, from $c .1850$ to 1900 and again during the second half of the 20th century. Correlation analysis between the statistical reconstruction of the area burned and the stand age distribution suggested that both proxies shared similar information on the fire activity. Correlation maps, however, indicated that variability in the statistical reconstructions was not necessarily representative of fire activity in all regions of the Boreal Shield.
\end{abstract}

\section{Introduction}

Climate is always changing owing to a number of factors such as changes in the earth's orbital, chemical composition of the atmosphere, solar variability, and volcanic activities (Bonan 2002). Thus, with a dynamic climate and a strong linkage between climate and forest fires, variations in historical observations of fire activity due to changes in the climate are expected (Flannigan and Harrington 1988; Johnson 1992; Swetnam 1993). Empirical data and model simulations suggested important changes in fire activity across the Canadian boreal forest in a context of a rapid change of the global climate (Bergeron et al. 2004a; Flannigan et al. 2005).
Already, the warming of the Northern Hemisphere, estimated at $\sim 0.6^{\circ} \mathrm{C}$ in the past century (Zhang et al. 2000 ; Folland et al. 2001; Houghton et al. 2001), has had a detectable influence on fire activity. According to analyses of forest stand age distributions, the lower fire activity since $c .1850$ reported in many regions of the Canadian boreal forest could, in part, reflect the impact of a changing climate (Masters 1990; Johnson and Larsen 1991; Larsen 1997; Bergeron et al. 2001, 2004a, 2004b; Tardif 2004).

Large forest fires in boreal Canada are often associated with upper level longwave ridging at boreal latitudes (Skinner et al. 1999, 2002). These large and persisting blocking 
high-pressure systems in the upper atmosphere cause air subsidence, resulting in typically sunny, warm days that lead to dry fuel conditions that can extend to several hundreds of kilometres (Newark 1975; Johnson and Wowchuk 1993; Bessie and Johnson 1995; Skinner et al. 1999, 2002). When the high-pressure systems have significant moisture or begin to break down, convective activity leading to numerous lightning strikes occurs and these ignite forest fires (Nash and Johnson 1996). Using synoptic dendroclimatology, Girardin et al. (2006) suggest that significant changes have occurred during the past two centuries with regard to the mean summertime intensity, frequency, and position of the upper level longwave ridges over boreal Canada. From c. 1851 to 1940 , evidence indicated that longwave ridges have increased in both frequency and magnitude over western Canada. Anomalous displacements of the storm track over western boreal Canada and intensified advection of humid air masses onto the eastern Boreal Shield likely contributed to the creation of moister conditions over large areas of the eastern Canadian boreal forest (Girardin et al. 2006).

Here we look at how climatic changes of the past two centuries may have translated in regard to annual fire activity on the Boreal Shield, Canada. First, six independent tree-ring reconstructions of summer drought developed by Girardin et al. (2006) were calibrated to develop 229-year statistical reconstructions of the fire activity. The six drought reconstructions were regressed against fire data from the large forest-fires database (LFDB; Stocks et al. 2003) and transfer functions were used to estimate annual area burned and fire occurrence (number of large fires per year) on the Boreal Shield at times during which there were no data. The methodology is similar to that employed by Westerling and Swetnam (2003) in their reconstruction of wildfire in the western USA. Second, tendencies in the occurrence of extreme fire years were tested using kernel occurrence rate estimation. We expected to see a decrease in the occurrence rate of extreme fire years, which would help to validate studies reporting lower fire activity since $c$. 1850 . Third, as a means of validating the statistical reconstructions, a comparison was made with the stand age distribution derived from a regional timesince-last-fire map. The map was developed by Bergeron et al. $(2004 b)$ at the transition zone between the mixedwood and coniferous boreal forests of south-western Quebec.

\section{Data and methods}

\section{Study area}

The Boreal Shield is a broad U-shaped zone that extends from northern Saskatchewan east to Newfoundland, passing north of Lake Winnipeg, the Great Lakes, and the St Lawrence River (Fig. 1). It has a strong continental climate characterized by long cold winters and short warm summers, but is modified by maritime conditions in its coastal margins in Atlantic Canada (Ecological Stratification Working Group

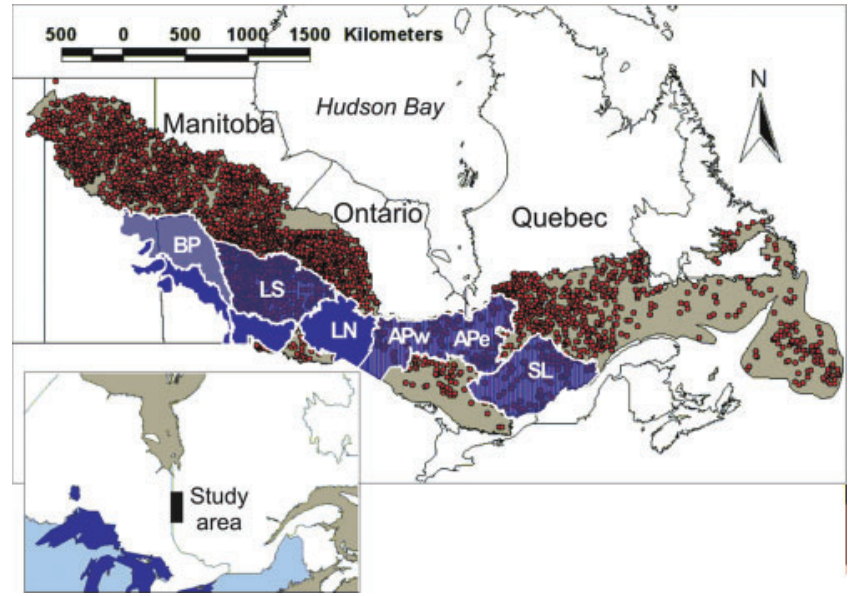

Fig. 1. Geographical locations of the six climate reconstructions developed by Girardin et al. (2006): Boreal Plains (BP), Lake Seul Upland (LS), Lake Nipigon (LN), Abitibi Plains west and east (APw and $\mathrm{APe}$ ), and Southern Laurentian (SL). The distribution of fires (dots) that occurred on the Boreal Shield, Canada, during 1959-1998 and the location of the study area (bottom map) from where the stand age distribution was developed (Bergeron et al. 2004b) are also shown.

1996). The mean annual temperature ranges between $-4^{\circ} \mathrm{C}$ in northern Saskatchewan and $5.5^{\circ} \mathrm{C}$ in the Avalon Peninsula of Newfoundland. Mean summer temperatures (June-August) generally range between $11^{\circ} \mathrm{C}$ and $15^{\circ} \mathrm{C}$ with the exception of a few areas in Labrador and western Newfoundland. Mean winter temperature (December-February) ranges between $-20.5^{\circ} \mathrm{C}$ in the west and $-1^{\circ} \mathrm{C}$ in the east. Mean annual precipitation ranges from $400 \mathrm{~mm}$ in northern Saskatchewan to $1000 \mathrm{~mm}$ in eastern Quebec and Labrador. The Great Lakes have a moderating effect on the climate of Boreal Shield areas of central Ontario, warming them in winter and cooling them in summer (Ecological Stratification Working Group 1996).

\section{Description of the area burned and fire occurrence data}

Forest fire data from the LFDB (Stocks et al. 2003) were used as predictands. These large fires (size $>200 \mathrm{ha}$ ) represent only a very small percentage of the fires but account for $\sim 97 \%$ of the area burned in Canada. The LFDB contains information on start location, estimated ignition date, cause, and final size of each fire. Even though weather and climate are the most important factors in fire activity, other factors such as fire suppression, land use, ignition sources, and fuel can influence fire statistics (Podur et al. 2002). Also, the quality of forestfire statistics varies over both time and space. The size of the protected area, the area that was effectively under fire management, is an increasing function of time in most provinces. Forest-fire management agencies have traditionally focused their efforts in areas where they judged fire might have its most significant impact on public safety, property, and forest resources. It is widely accepted that not all the fires that occurred in lower priority areas were detected, reported, and 
included in the annual fire statistics. Also, relatively large fires ( $>200 \mathrm{ha}$ ) are much more likely to be observed and recorded than smaller fires. According to Podur et al. (2002), one can assume that there is something to be learned from a careful analysis of the fire data in spite of its flaws.

Data from fires that occurred on the Boreal Shield were compiled and two time series covering the 1959-1998 period were created, that is annual area burned (expressed in ha) and fire occurrence (number of large fires per year). The total area covered by the fires from 1959 to 1998 (Fig. 1) equalled $26.12 \mathrm{Mha}$. Of that total, $29.8 \%$ of annual area burned occurred in Saskatchewan, 26.1\% in Manitoba, 23.8\% in Ontario, and $15.8 \%$ in Quebec. The total number of large fires equalled 4052 . Of that total, $18.2 \%$ occurred in Saskatchewan, $28.8 \%$ in Manitoba, 30.5\% in Ontario, and $18.4 \%$ in Quebec.

Two data transformations were applied to the area burned and fire occurrence data. First, Kolmogorov-Smirnov tests indicated right-skewness (Zar 1999) in the annual area burned and fire occurrence frequency distributions (for area burned, $P<0.001$; for fire occurrence, $P=0.009$ ). The logarithmic transformation (LOG) was found to provide an adequate data transformation to meet the normality requirement $(P>0.200)$. Second, a linear trend removal was performed on the LOG-scaled data using a least squares fitting, and departures were extracted. We found that removal of a positive trend from the fire data significantly improved the models' verification statistics (described below). The procedure was further justified by the absence of detectable trends in components of the fire weather index covering the Boreal Shield (Amiro et al. 2004; Girardin et al. 2004a).

\section{Description of the predictors}

The summer drought reconstructions used in the present work (Fig. 2; Table 1) were developed by Girardin et al. (2006) from a network of 120 well-replicated tree-ring chronologies developed mainly on the Boreal Shield. This set of chronologies originated from 13 tree species; all of the chronologies covered the minimum interval 1866-1985.

The areas covered by the six summer drought reconstructions represent six climate regions (Fig. 1), with boundaries approximating ecoregions defined by the Ecological Stratification Working Group (1996). These climate regions from west to east are the Boreal Plains (BP), the Lac Seul Upland and Lake of the Woods (LS), the Lake Nipigon (LN), the Abitibi Plains west and east (APw and APe), and Southern Laurentian (SL). Each drought reconstruction was developed independently from the others, that is, there was no data overlap between regions. The drought reconstruction procedure used a varying time series approach (Cook et al. 2002; Luterbacher et al. 2002; Girardin et al. 2004b), in which a calibration model was made using the maximum available chronologies for a particular region. Thereafter, the shortest
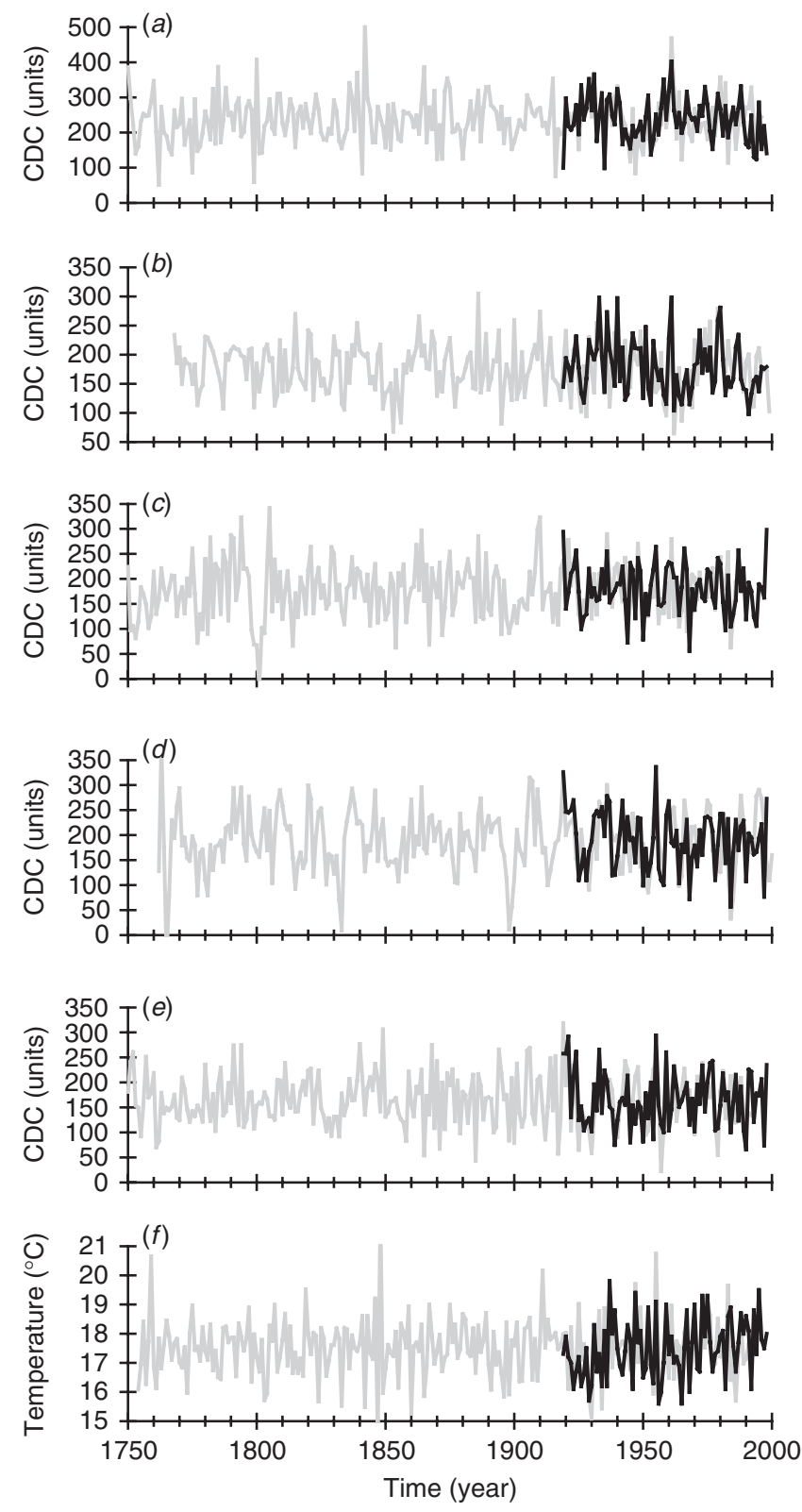

Fig. 2. (a) to (e) Reconstructions of the mean July Canadian drought code (CDC) for the Boreal Plains, Lake Seul Upland, Lake Nipigon, and Abitibi Plains west and east regions. The CDC scale ranges from soil saturation (zero) to extreme drought (>approximately 300). $(f)$ Reconstruction of the Southern Laurentian mean July to August temperature. Bold line is instrumental data (period 1913-1998). Variance in the reconstructions has been adjusted to correspond to instrumental data. Refer to Table 1 for statistics.

chronologies were removed one by one and sub-calibrations were computed at each step until a minimum of five chronologies was left for calibration. The final drought reconstructions shown in Fig. 2 were built after piecing together segments of the sub models.

The drought reconstructions were considered reliable as proxies of past year-to-year and decade-to-decade variability 
Table 1. Statistics of the six climate reconstructions (developed by Girardin et al. 2006)

The period covered by each reconstruction, the number of chronologies from which the reconstructions were developed, and the maximum amount of variance $R^{2}$ in the instrumental data accounted for by each reconstruction (period 1919-1984) are indicated. Also shown are the first and second eigenvectors of the principal component analysis for the period 1769-1998 . CDC, Canadian drought code

\begin{tabular}{llccccr}
\hline Reconstruction & Variable & Period covered & No. chronologies & $R^{2}(\%)$ & Eigenvector 1 & Eigenvector 2 $^{\mathrm{C}}$ \\
\hline Boreal Plains & July CDC & $1718-1996$ & 13 & 39 & 0.25 & 0.79 \\
Lake Seul & July CDC & $1768-1999$ & 25 & 50 & 0.58 & 0.49 \\
Lake Nipigon & July CDC & $1680-1987$ & 24 & 36 & 0.73 & 0.04 \\
Abitibi Plains west & July CDC & $1762-2001$ & 13 & 34 & 0.72 & -0.17 \\
Abitibi Plains east & July CDC & $1683-1992$ & 20 & 46 & 0.55 & -0.37 \\
Southern Laurentian & Jul-Aug temperature & $1754-1994$ & 25 & 44 & 0.40 & -0.46 \\
\hline
\end{tabular}

${ }^{\mathrm{A}}$ Eigenvectors show the correlation coefficient between a given principal component and the reconstructions. ${ }^{\mathrm{B}, \mathrm{C}}$ Accounted for $31.9 \%$ and $20.5 \%$, respectively, of the variance in the six reconstructions.

in drought for the period covering the late 1760 s to present. Because the age/size-related trend was removed from the treering measurement series, the drought reconstructions contain no information relative to centennial-long climate changes. The tree-ring width chronologies for the drought reconstructions were standardised with cubic splines, such that mainly annual to decadal scale variance was retained in the chronologies, and hence, in the drought reconstructions. For example, $99 \%$ of the variance contained in frequencies lower than 19 years and $50 \%$ of the variance in frequencies lower than 60 years was preserved. The mean length of measurement series (mean age of 137 years) was considered insufficiently long to allow robust reconstruction of low frequency climatic variations. For the purpose of the present study, four of the six reconstructions were updated to 1998 using available instrumental data.

Five of the six drought reconstructions were reconstructions of the July Canadian Drought Code (CDC), a proxy for the average moisture content of deep and compact organic layers for a season approximating May to July. Over $78 \%$ of total area burned in Canada occurs during this season (Stocks et al. 2003). The CDC is a component of the Canadian Forest Fire Weather Index System (Turner 1972; Van Wagner 1987; Girardin et al. 2004a) and is used daily by the fire management agencies across Canada to monitor fire danger. It is a useful indicator of seasonal drought and shows the likelihood of fire involving the deep duff layers and large logs. A CDC rating of 200 is high and $\sim 300$ or more is extreme, indicating that fire will involve burning deep sub-surface and heavy fuels. The sixth drought reconstruction was one of July to August mean temperatures. It was developed as an alternative to the unsatisfactory drought predictive skills of the treering chronologies from the SL region. Despite the absence of a drought signal, the temperature reconstruction provides valuable information on past climate variability, notably on the occurrence of mid-summer warm spells and persistent ridging (Girardin et al. 2006). Hereafter, the temperature reconstruction is also referred to as a 'drought' reconstruction for consistency throughout the paper.
The six drought reconstructions, held together on a common interval 1769-1998, were transformed into non-rotated principal components (PCs) to remove multicollinearity (Legendre and Legendre 1998). Only the first and second PCs, accounting for $31.9 \%$ and $20.5 \%$ of the variance respectively, were retained for subsequent analyses. The first PC was associated with a large pattern of drought variance across the six regions, with a centre over the $\mathrm{LN}$ and $\mathrm{APw}$ climate regions (Table 1). The second PC was associated with a dipolar structure in drought severity between the western and eastern regions. Synoptic analyses between these two PCs and mid-tropospheric geopotential heights and global sea surface temperatures indicated that the variability in PC1 and PC2 was representative of dominant synoptic scale modes of summertime climate variability across Canada and the North Pacific sector (Girardin et al. 2004a, 2006). Because drought conditions during a given year may affect the spring fire season of the following year (in some situations winter precipitation may be insufficient to prevent a seasonal drought carryover, Van Wagner 1987), the two PCs were lagged by 1 year and also included in the analyses. The program used for the principal component analysis was CANOCO 4.0 (Ter Braak and Smilauer 1998).

\section{Statistical reconstruction of the area burned and fire occurrence}

A stepwise multiple regression employing a backward selection was used to calibrate the PCs against the LOG-scaled annual area burned and fire occurrence data (period 19591998),

$$
Y_{\mathrm{LOG} j}=\alpha+\beta_{1} X_{1 j}+\beta_{2} X_{2 j}+\cdots+\beta_{m} X_{m j}+\epsilon_{j}
$$

where $Y_{\mathrm{LOG} j}$ was the fire data, $X_{j}$ the PCs (two present and two prior year lags: total four predictors), $\beta$ the regression coefficients, and $\epsilon_{j}$ the error. The stability of the regression model was tested after conducting two sub-calibrations of the period 1959-1978 and 1979-1998 using the selected variables in Eqn 1. The strength of the relationship between reconstruction and observation over the independent verification 
periods 1979-1998 and 1959-1978, respectively, was measured by the reduction of error (RE), sign test, and the product means test (PM) discussed in Cook et al. (1994) and Cook and Kairiukstis (1990) (see Appendix 1). The RE provides a sensitive measure of reconstruction reliability. Whenever RE is greater than zero, the reconstruction is considered as being a better estimation of climate than the calibration period mean. A significant sign test result indicates good fidelity in the direction of year-to-year change in the real and reconstructed data. A significant PM test result indicates that the magnitude and the direction of these changes are statistically significant. The program used for the stepwise multiple regression analyses was SYSTAT 9.1 (SYSTAT 1998). The program used for calculation of the RE and PM verification statistics was VFY (Holmes 1999).

Finally, the LOG-scaled fire data were scaled to their original variance using the equation (Baskerville 1971):

$$
\hat{Y}_{j}=10 \operatorname{EXP}\left(\hat{Y}_{L O G j}+\hat{\sigma}^{2} / 2\right) .
$$

The strength of the relationship between reconstruction and observation over the independent verification periods was retested on these EXP-scaled fire data. Additionally, the difference in mean of reconstructed fire activity at the time of the 5 highest and remaining 15 instrumental fire years was tested using the non-parametric Mann-Whitney U test statistic (Zar 1999). A significant test result indicates a tendency for the statistical reconstruction to reproduce with confidence years of extreme fire activity.

The potential of the statistical reconstruction to approximate fire activity across the Boreal Shield was evaluated as follows. Pearson's correlation coefficients were calculated between the statistical reconstructions (area burned and fire occurrence) and the instrumental fire records from 11 ecoregions of the Boreal Shield. Ecoregions with little or no fire activity were dropped from the analysis (Rainy River [ecoregion no. 92], Thunder Bay-Quetico [no. 93], and Algonquin-Lake Nipissing [no. 98]). Ecoregions located in the Maritimes were also dropped (nos 102-116). The Abitibi Plains (no. 96) and Lake Temiscaming Lowland (no. 97) ecoregions were merged to increase sample size. The Pearson's correlation coefficients were calculated with $95 \%$ confidence intervals using a non-parametric stationary bootstrap. This technique resamples blocks of data pairs to account for the presence of serial correlation in the time series. The confidence intervals allow testing whether the correlation between two serially dependent time series is significant. When the confidence interval contains zero, the hypothesis of 'no correlation' cannot be rejected at the 95\% level. Analyses were conducted on LOG-scaled fire data. The software used for the correlation analyses was PearsonT (Mudelsee 2003).

\section{Description of the forest stand age distribution}

As a means of validating the statistical reconstructions of the fire activity, a comparison was made with a stand age distribution located at the transition zone between the mixedwoods and coniferous boreal forests of south-western Quebec. The stand age distribution was derived from a regional time-since-last-fire map. The portion of the study area encompassed a territory of $15000 \mathrm{~km}^{2}$ distributed on the Abitibi Plains and Abitibi Temiscaming Lowland (APe) of the Boreal Shield (Fig. $1 ; 78^{\circ} 30^{\prime} \mathrm{W}$ to $79^{\circ} 30^{\prime} \mathrm{W}$ and $48^{\circ} 00^{\prime} \mathrm{N}$ to $\left.50^{\circ} 00^{\prime} \mathrm{N}\right)$. The area is located within the Clay Belt of Ontario and Quebec, a large physiographic unit of clay deposits left by pro-glacial Lake Ojibway (Veillette 1994). In the northernmost part of the study area, the topography is generally flat, and the most important surficial deposit is organic soil, followed by clay deposit (Robitaille and Saucier 1998). In the south, rolling topography and clay deposits are dominant, followed by organic deposits. There are also more lakes, especially large lakes ( $>5000 \mathrm{ha}$ ) in the south. The mean annual temperature ranges from somewhat over $1^{\circ} \mathrm{C}$ in the southern sections of APe to almost $0^{\circ} \mathrm{C}$ in the northern sections. A cold arctic air mass dominates the area during winter with the mean temperature in January ranging from $-17^{\circ} \mathrm{C}$ in the south to $-20^{\circ} \mathrm{C}$ in the north. In summer, a relatively moist tropical air mass and a typically dry polar air mass take turns. July mean temperature ranges from $17^{\circ} \mathrm{C}$ in the south to $16^{\circ} \mathrm{C}$ in the north. Mean annual precipitation ranges from over $900 \mathrm{~mm}$ in the south-east to $850 \mathrm{~mm}$ in the north (Environment Canada 2002). European colonisation in the region mainly started in the 1910 s. Efficient fire suppression only began in the 1970s and it is only since 1980 that fires are suppressed in the northern half of the studied area (Bergeron et al. 2001, 2004b).

Basically, a time-since-last-fire map (or forest stand initiation map; Johnson and Gutsell 1994) was created using field and archival data. Reports of individual fires were available since 1923, and fires were completely mapped since 1945. Moreover, there are two types of archived data: fires smaller than 800 ha are geo-referenced as point data, whereas the larger fires are available in polygon format. Aerial photographs (some dating from the late 1920s and 1930s) made it possible to delineate boundaries. The study area was divided into $100-\mathrm{km}^{2}$ grids where at least one site would be visited. In each site, five disks or increment cores were collected, preferably from pioneer tree species. When available, snags and cross sections of trees bearing fire scars were also collected. In total, 315 sites were sampled for an average of one sample per $50 \mathrm{~km}^{2}$. It is generally recognised that the fire regime of the boreal forest is characterized by a few fires that burn large areas (Stocks et al. 2003) and in this context, our map allows for a good estimation of area burnt per year. The time-since-last-fire map was reconstructed using all available information. In one third of the cases, it represents the age of the oldest tree sampled belonging to the post-fire cohort of trees. In most cases $(2 / 3)$, however, when the cohort of trees didn't remain, a minimal fire date was established based on the age of the oldest tree sampled (Bergeron et al. 2004b). 
Those minimum times-since-last-fires were considered as censored data in further analysis.

In order to estimate the area covered by each fire year, the fire boundaries obtained from the archival data or the photo interpretation of old aerial photographs were digitized and included into a GIS database (Bergeron et al. 2004b). All the sample point locations were also included, together with the dendrochronological data. This allowed us to precisely map the time-since-last-fire for fires that occurred after 1880. For older fire years, because precise fire limits were not delineated, an estimation of the area burned was obtained by interpolating the fire date between each sample point using the Thiessen method (Linsley et al. 1982) in Arcview. However, because of the lack of precision in the estimation of the fire date from the field data, all data were presented in 10-year age classes (Bergeron et al. 2004b).

From this dataset, we were interested in characterizing the departure from the average area burned per decade. Because recent fires tend to eliminate information relevant to past fires, an exponential curve was fitted to the stand age distribution using survival analysis (Proc Lifereg; SAS Institute 1990). This procedure allowed us to estimate the average burned rate for the entire data period while taking into account the imprecision in the fire data collection originating from censored data. The mean burn rate for the whole period was estimated at $0.58 \%$ per year with $95 \%$ confidence intervals $(0.52$; 0.66) (Bergeron et al. 2004b). Departures from the average area burned per decade were calculated by subtracting the theoretical exponential curve from the stand age distribution.

\section{Statistical analysis}

\section{Tendencies in the occurrence rate}

Changes in the occurrence rate of extreme fire events, defined by the number of events per year, were analysed using kernel functions. Kernel estimation allows detailed inspection of time-dependent event occurrence rates and assessment of significant changes with the help of confidence bands. In spite of the fact that centennial variations have been removed from the statistical reconstruction of the fire activity during processing of the tree ring-width series, year-to-year and decade-todecade variability has been entirely preserved. The statistical reconstructions of the fire activity are therefore suitable for detection of trends in the occurrence rate of extreme events. We used a Gaussian kernel, $K$, to weigh observed extreme fire activity event dates, $T(i), i, \ldots, N$ (total number of events), and calculate the occurrence rate, $\lambda$, at time $t$ as:

$$
\lambda(t)=\sum_{i} K((t-T(i)) / h) .
$$

The number of extreme fire activity events under analysis was set to equal the highest $10 \%$ percentile. The selection of the bandwidth ( $h=15$ years) was guided by cross-validation.
Confidence bands $(90 \%)$ around $\lambda(t)$ were determined using the following bootstrap technique. $N$ simulated events were drawn from $T(i)$ with replacement and simulated $\lambda$ calculated. This procedure was repeated 10000 times, and a percentile- $t$ confidence band was calculated. Detected trends in occurrence rate were confirmed for the measured interval using the statistical test described by Cox and Lewis (1966). This parametric procedure tests the null hypothesis 'constant occurrence rate' against one-sided alternatives such as 'increasing occurrence rate'. One seeks to disprove the hypothesis of a constant occurrence rate when the $P$ value is lower than 0.05 . Kernel occurrence rate estimation with bootstrap confidence band construction was introduced into the analysis of climate extremes by Mudelsee et al. (2003); a detailed description is given by Mudelsee et al. (2004). The software used for occurrence rate estimation was XTREND (Mudelsee 2002).

\section{Statistical reconstruction $\mathrm{v}$. stand age distribution}

The departures from the exponential fit of the stand age distribution (in 10-year age classes) were compared with 10 -year non-overlapping sums of the annually resolved statistical reconstruction of the Boreal Shield area burned using correlation analyses. Pearson's correlation coefficients were calculated using both ranked time series with the nonparametric stationary bootstrap procedure described earlier. The analysis was repeated by doing 1-year backward and forward lags of the statistical reconstruction of the area burned, and this up to 10 years. There is a general agreement that ageing shade-tolerant tree species from tree rings often leads to an underestimation of the true age (DesRochers and Gagnon 1997; Kneeshaw and Claveau 2001; Wong and Lertzman 2001; Girardin et al. 2002; Gutsell and Johnson 2002). The time-since-last-fire may also exceed the age of the oldest trees because of individual tree mortality (Fox 1989). This may cause post-fire tree recruitment events to follow fire events by some lagged set of years. We therefore expected to find a lag between episodes of important stand recruitment and episodes of large fire activity as revealed by the statistical reconstruction.

\section{Results}

Statistical reconstruction of the fire activity on the Boreal Shield

The stepwise regression model indicated that $30.6 \%$ of the variance (adj. $R^{2}=26.8 \%$ ) in the LOG-scaled annual area burned over the Boreal Shield was accounted for by the first principal component of the six drought reconstructions. The model's equation:

$$
Y_{\mathrm{LOG} j}=5.56+0.14 \mathrm{PC}_{j-1}+0.22 \mathrm{PC}_{j},
$$

indicated that whereas the current year drought condition $\mathrm{PC}_{j}$ accounted for the largest amount of variation in area 
Table 2. Calibration and verification statistics of the Boreal Shield LOG-scaled area burned and fire occurrence reconstructions Verification statistics calculated on EXP-scaled data are shown in parentheses

\begin{tabular}{|c|c|c|c|c|c|c|}
\hline \multirow[b]{2}{*}{ Calibration period } & \multicolumn{3}{|c|}{ Area burned } & \multicolumn{3}{|c|}{ Fire occurrence } \\
\hline & $1959-1998^{\mathrm{G}}$ & 1959-1978 & 1979-1998 & $1959-1998^{\mathrm{H}}$ & 1959-1978 & 1979-1998 \\
\hline Verification period & - & 1979-1998 & 1959-1978 & - & 1979-1998 & 1959-1978 \\
\hline \multicolumn{7}{|l|}{ Calibration } \\
\hline$R$-square & 0.31 & 0.31 & 0.32 & 0.45 & 0.32 & 0.74 \\
\hline Standard error & 0.40 & 0.47 & 0.36 & 0.22 & 0.25 & 0.15 \\
\hline \multicolumn{7}{|l|}{ Verification } \\
\hline Correlation $^{\mathrm{B}}$ & - & $0.56^{\mathrm{A}}$ & $0.54^{\mathrm{A}}$ & - & $0.57^{\mathrm{A}}$ & $0.54^{\mathrm{A}}$ \\
\hline Reduction of error ${ }^{\mathrm{C}}$ & - & $0.29^{\mathrm{A}}\left(0.23^{\mathrm{A}}\right)$ & $0.29^{\mathrm{A}}\left(0.32^{\mathrm{A}}\right)$ & - & $0.54^{\mathrm{A}}\left(0.40^{\mathrm{A}}\right)$ & $0.21^{\mathrm{A}}\left(0.14^{\mathrm{A}}\right)$ \\
\hline Product means test ${ }^{\mathrm{D}}$ & - & $2.51^{\mathrm{A}}\left(2.54^{\mathrm{A}}\right)$ & $1.14(1.00)$ & - & $2.29^{\mathrm{A}}\left(4.39^{\mathrm{A}}\right)$ & $2.06^{\mathrm{A}}(1.28)$ \\
\hline Sign test ${ }^{\mathrm{E}}$ & $29 / 11^{\mathrm{A}}\left(27 / 13^{\mathrm{A}}\right)$ & $14 / 6\left(17 / 3^{\mathrm{A}}\right)$ & $14 / 6(11 / 9)$ & $28 / 12^{\mathrm{A}}\left(30 / 10^{\mathrm{A}}\right)$ & $16 / 4^{\mathrm{A}}\left(17 / 3^{\mathrm{A}}\right)$ & $12 / 8(13 / 7)$ \\
\hline $\mathrm{U}$ test $^{\mathrm{F}}$ & - & $0.016^{\mathrm{A}}$ & 0.176 & - & $0.003^{\mathrm{A}}$ & $0.040^{\mathrm{A}}$ \\
\hline
\end{tabular}

${ }^{\text {A }}$ Verification test significant at $P<0.05$ or considered satisfactory. ${ }^{\mathrm{B}}$ Significant at $P<0.05$ if $r>0.49 .{ }^{\mathrm{C}}$ Considered satisfactory if $>0$. Whenever RE is greater than zero, the reconstruction is considered as being a better estimation of climate than the calibration period mean. ${ }^{\mathrm{D}}$ Considered significant at $P<0.05$ if $>1.73$. A significant product means test result indicates that the magnitude and the direction of year-to-year changes are statistically significant. ${ }^{\mathrm{E}}$ Agreement/disagreement: $P<0.05$ if sign test $\geq 16 / 4$. For the calibration of $1959-1998, P<0.05$ if sign test $\geq 27 / 13$. A significant sign test result indicates good fidelity in the direction of year-to-year changes in the real and reconstructed data. ${ }^{\mathrm{F}} P$ value of the Mann-Whitney $\mathrm{U}$ test statistic. A significant test result indicates a tendency for the reconstruction to reproduce with confidence extreme fire activity. ${ }^{\mathrm{G}}$ Prediction Eqn 3; see text. Standard errors for $\alpha=0.063$, $\beta_{1}=0.070, \beta_{2}=0.068$. ${ }^{\mathrm{H}}$ Prediction Eqn 4; see text. Standard errors for $\alpha=0.034, \beta_{1}=0.035, \beta_{2}=0.035$.

burned on the Boreal Shield, part of the variance could also be explained by the previous year drought conditions $\mathrm{PC} 1_{j-1}$. In a separate run in which PCs were derived from instrumental drought data (shown in Fig. 2), we found that the same predictors $\mathrm{PC}_{j-1}$ and $\mathrm{PC}_{j}$ explained a significant amount of the area burned variance during the period 1959-1998 $\left(R^{2}=29.9 \%\right.$ and adj. $\left.R^{2}=26.1 \%\right)$.

Similarly, the stepwise regression model indicated that $\mathrm{PC}_{j}$ and $\mathrm{PC}_{j-1}$ accounted for $44.8 \%$ of the variance (adj. $R^{2}=41.8 \%$ ) in the LOG-scaled annual fire occurrence:

$$
Y_{\mathrm{LOG} j}=1.90+0.13 \mathrm{PC}_{j-1}+0.13 \mathrm{PC}_{j}
$$

In this model, however, both current and previous years' summer drought conditions had similar weight in the estimation of fire activity. Similar results to those of Eqn 5 were obtained after using PC derived from instrumental drought data (Fig. 2) as fire occurrence predictors $\left(R^{2}=45.5 \%\right.$ and adj. $\left.R^{2}=42.6 \%\right)$.

Verification statistics of the strength of the sub-calibration models indicated significant predictive skills of the statistical reconstructions of the fire activity (Table 2). Positive $\mathrm{RE}$ and significant correlation coefficients indicated tendencies for the area burned and fire occurrence to reproduce with confidence both high and relatively low frequency variations in fire activity. Other tests, however, indicated difficulties to reproduce the direction of year-to-year area burned, with significance levels of the sign test at $P=0.20$. The PM tests of the most recent verification period (19791998) nevertheless indicated some predictive skills of the statistical reconstruction of the area burned to reproduce the magnitude and direction of changes. The statistical reconstruction of the fire occurrence showed better predictive skills, with one significant sign test and two significant PM tests. Verification statistics computed on EXP-scaled (a)

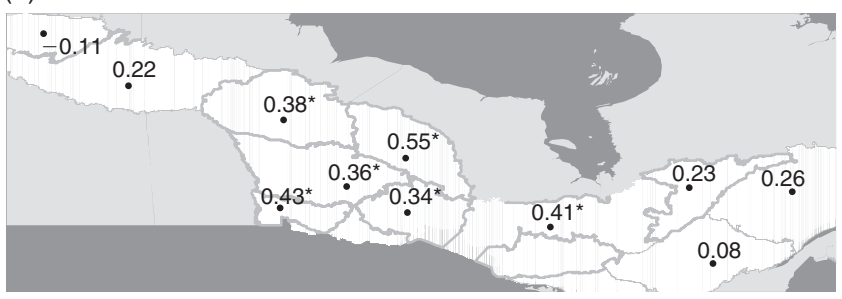

(b)

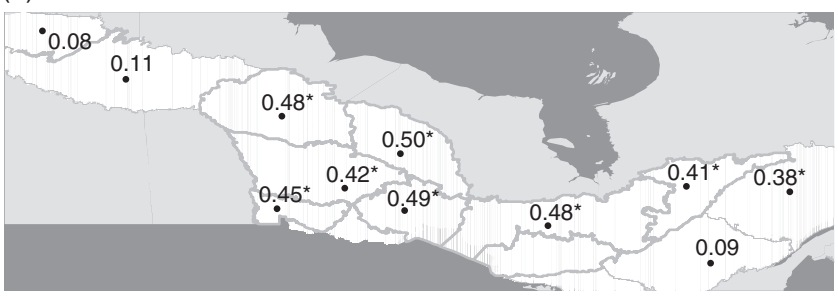

Fig. 3. Correlation maps showing the relationships between instrumental fire data from 11 ecoregions and statistical reconstructions of the (a) area burned and (b) fire occurrence (period of analysis: 1959-1998). Correlation coefficients $r$ are significant at $P<0.05$ when $r \geq 0.31$. Significant coefficients as identified by the bootstrap analyses are shown with *.

data (Table 2) indicated that rescaling the fire data to its original variance did not significantly affect the strength of the relationship. The Mann-Whitney $U$ test statistic further indicated a tendency for the statistical reconstructions, particularly those of fire occurrence, to reproduce with confidence conditions of extreme fire activity.

Area burned and fire occurrence correlation maps were created in order to evaluate the potential of the statistical reconstructions to approximate fire activity across the Boreal Shield. Figure 3 shows that the statistical reconstructions 


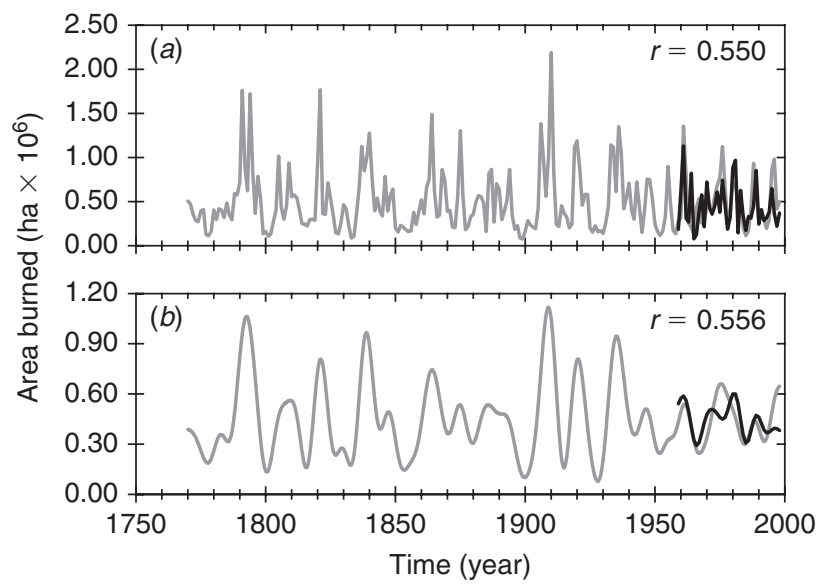

Fig. 4. (a) Boreal Shield statistical reconstruction of the area burned (period 1770-1998) against the instrumental fire record (bold line, period 1959-1998). Variance in the instrumental fire record was adjusted to correspond to the reconstruction. $(b) 10$-year window polynomial curve (order 8) of reconstructed and instrumental area burned. The Spearman correlation coefficient between the two time series for their common interval is indicated $(n=40)$.

shared common variability with instrumental fire data from several ecoregions. This was particularly true in regard to fire occurrence, for which significant correlation coefficients were obtained for eight ecoregions out of 11 . The statistical reconstructions, nevertheless, appear not to be representative of fire activity in the north-western and south-eastern locations of the Boreal Shield. Furthermore, reconstruction models conducted on fire statistics from an aggregate of ecoregions indicated that a better fit between reconstructed and estimated data could be obtained. For instance, the exclusion of north-west and south-east ecoregions from the fire statistics slightly improved the calibration $R^{2}$ and reconstruction predictive skills of fire occurrence $\left(R^{2}=50.7 \%\right.$ and adj. $R^{2}=48.0 \%$; $\mathrm{RE}=0.58$ and 0.37$)$. However, the calibration model $\left(Y_{\mathrm{LOG} j}=1.72+0.16 \mathrm{PC}_{j-1}+0.16 \mathrm{PC}_{j}\right) \mathrm{did}$ not differ much from that given by Eqn 5 . Therefore, models calibrated on the entire Boreal Shield fire statistics were retained for subsequent analysis.

\section{Fire activity since 1770}

Instrumental area burned and fire occurrence are highly correlated (Spearman $r=0.81$ ). A similar statement can be made for the statistical reconstructions of the area burned (Fig. 4) and fire occurrence (Appendix 1, Fig. A1) $(r=0.98)$. For means of simplicity, the following analyses were therefore carried out on the statistical reconstruction of the area burned only.

The statistical reconstruction of the area burned is presented in Fig. $4 a$ over its full period 1770-1998. The smoothed curve is presented in Fig. $4 b$. This curve represents decade-to-decade changes in fire activity. Note that both estimated and instrumental curves had their lower frequency
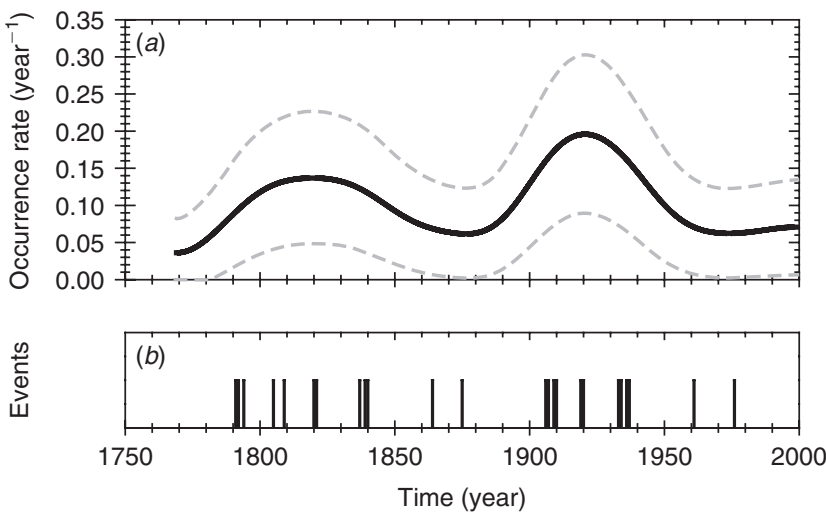

Fig. 5. (a) Occurrence rate of $(b)$ extreme area burned events $(n=24)$ on the Boreal Shield. The extreme events were detected in the statistical reconstruction of the area burned (Fig. 4) using median smoothing (smoothing parameter, $k=114$ ) and a threshold of $z=3.0$, see Mudelsee (2006) for details. The extreme events were further analysed using a Gaussian kernel, a bandwidth of $h=15$ years and bootstrap simulations $\left(n_{\mathrm{sim}}=10000 ; t_{\mathrm{obs}-l}=1769, t_{\mathrm{obs}-r}=1999\right)$, see Mudelsee et al. $(2003$, 2004). The bandwidth was determined using a cross-validation criterion (Mudelsee et al. 2004: eqn 5 therein). This yielded (a) occurrence rate (bold line) and $90 \%$ confidence bands (dashed lines). A sensitivity analysis, in which parameters $z, h$, and $k$ were varied around the used values, confirmed the robustness of the result.

removed and do not retain low-frequency variations at the multiple decadal scale. Estimated fire data, however, generally showed decadal variations similar to those of instrumental data (Fig. 4b; Appendix 1, Fig. A1). The statistical reconstruction of the area burned (Fig. $4 a$ ) indicated that episodes of succeeding years of extensive fire activity occurred in 1789-1796, 1820-1823, 1837-1841, 18621866, 1906-1912, 1919-1922, 1933-1938, and 1974-1977. The year 1910 was estimated as the year of most extreme fire activity with over 2.18 Mha in area burned and over 261 large forest fires of size greater than 200 ha (according to the statistical reconstruction of the fire occurrence, Appendix 1, Fig. A1). Years 1791, 1794, 1821, 1864, 1906, and 1961 were, among others, also estimated as years of extreme fire activity. The smoothed curve (Fig. $4 b$ ) suggested the prevalence of a period of reduced large fire events from the 1850 s to the early 1900 s. A decrease of fire activity was also estimated for the second half of the 20th century. These longer-term tendencies found by visual inspection were corroborated by the kernel occurrence rate estimation (see below).

Analysis of occurrence rates estimation (Fig. $5 b$ ) indicated low occurrence rates of extreme area burned events (Fig. $5 a$ ) during the second half of the 19th century and again during the late 20th century. The kernel occurrence rate estimations found 1 year of extreme area burned for every 16 years during the $1860 \mathrm{~s}-1870 \mathrm{~s}$ and $1970 \mathrm{~s}-1980 \mathrm{~s}$. This contrasted with extreme area burned occurrence rates as high as one for every 7 years during the 1820 s and one for every 5 years during the 1920s. The analysis did not reveal significant trends in 

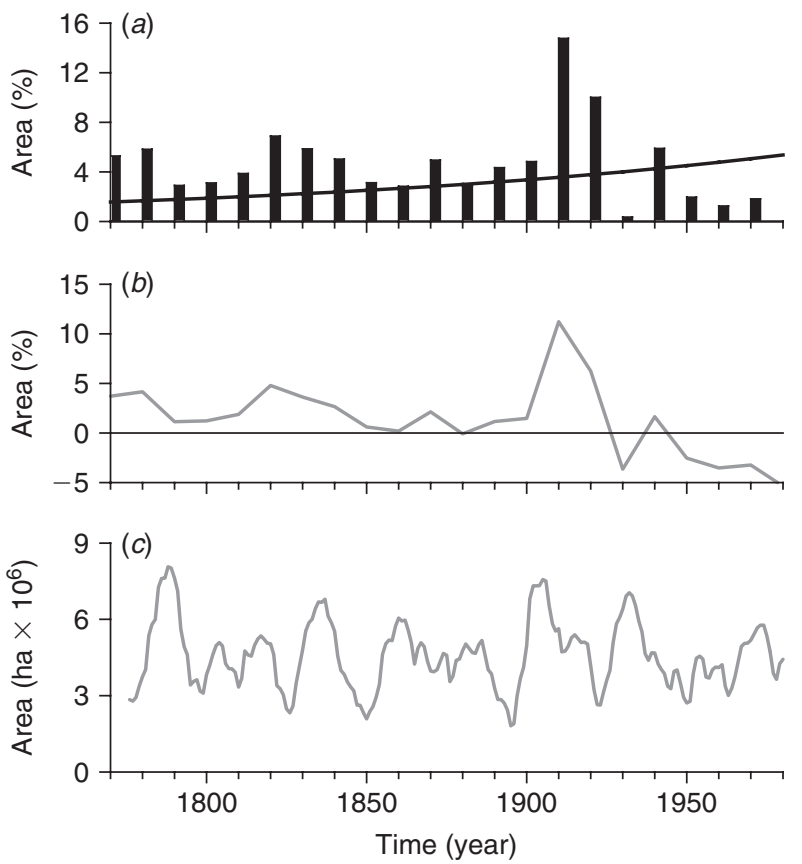

Fig. 6. (a) Vertical bars: Stand age distribution for the area located at the transition zone between the mixedwoods and coniferous boreal forests of south-western Quebec in 10-year age class. The negative exponential curve shows the theoretical stand age distribution expected under a constant fire regime. (b) Departures from the exponential fit to the stand age distribution (in 10-year age classes). (c) 10-year overlapping sums of the Boreal Shield reconstructed area burned.

occurrence rate for the whole period of analysis (1770-1998, $P=0.47)$, neither for $c .1820-1880(P=0.14)$. But a significant trend toward a decrease in the occurrence rate of extreme area burned events was detected in the analysis of 1920-1998 $(P=0.03)$.

\section{Comparison with the regional stand age distribution}

The inter-decadal variability in the statistical reconstruction of the area burned was compared with the stand age distribution (in 10-year age classes) of Bergeron et al. (2004b) (Fig. 6). The stand age distributions, expressed in percentage of the study area, showed a distinct decrease in area originating from fire during the 20th century (Fig. 6a). This shift in the fire activity is accentuated when looking at the departures from the exponential fit to the stand age distribution (Fig. 6b).

A visual inspection of Fig. $6 b, c$ reveals that the stand age distribution and the statistical reconstruction of the area burned shared similar inter-decadal variability, particularly from 1800 to 1950 . The similarities between the two were further accentuated when comparing the area burned kernel estimation of occurrence rate (Fig. 5) with the stand age distribution (Fig. 6a,b). The comparison suggests that the stand age distribution (i.e. peaks in the 1820s-1830s and 1910s$1920 \mathrm{~s}$, and troughs in the 1860s-1880s and 1950s-1960s) could be a function of extreme annual fire events clustered in (a)

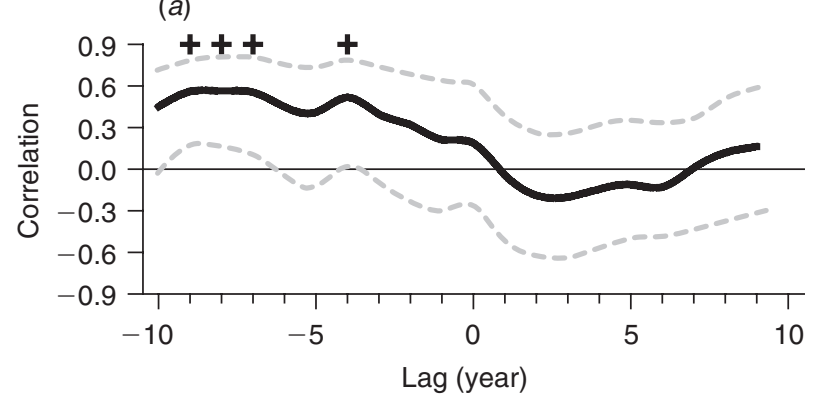

(b)

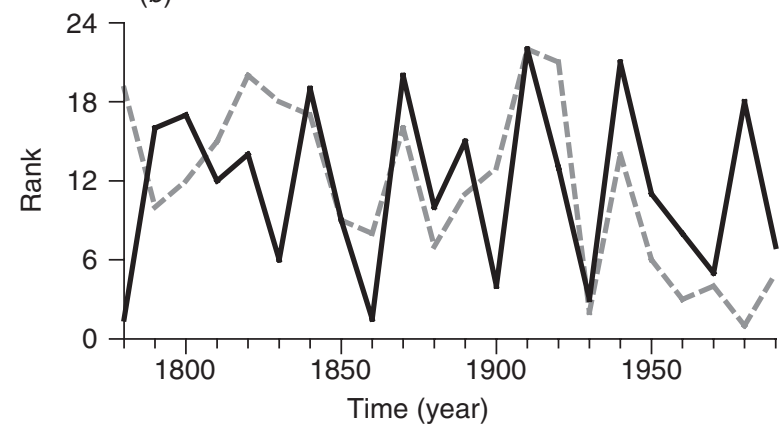

Fig. 7. (a) One to ten-year backward and forward lag Pearson correlation coefficients (solid line) between ranked departures from the exponential fit to the stand age distribution and ranked decadal sums of the area burned reconstruction. The dashed lines show the $95 \%$ confidence interval as calculated using the software PearsonT (Mudelsee 2003). When the confidence interval contains zero, the hypothesis of "no correlation' cannot be rejected at the $95 \%$ level. Significant correlations are marked with ' + '. (b) Ranked departures from the exponential fit to the stand age distribution (dashed line) against ranked decadal sums of the area burned reconstruction corresponding to -8 -year lag (solid line). The Pearson coefficients in $(a)$ were calculated over the interval $1790-1970(n=19$ decades $)$; trends in ranked data were removed prior to analysis.

time. Discrepancies between the two records however were noted. The stand age distribution (Fig. $6 b$ ) showed a peak of stand initiation in the 1910s that largely exceeded that of the area burned statistical reconstruction (Fig. 6c). Also, important estimated area burned in the late 1790 s had no equivalent in the stand age distribution. A similar observation was made after comparing the stand age distribution with the regional APe drought reconstruction (Fig. 2e): the stand initiation peak of the $1770 \mathrm{~s}-1780 \mathrm{~s}$ did not correspond to a period of high drought severity.

The relation between Fig. $6 b$ and $c$ was quantified by calculating Pearson correlation coefficients between ranked time series of departures from the exponential fit to the stand age distribution and 10-year non-overlapping sums of reconstructed area burned. (As fire dating uncertainty increases with stand age, we expected episodes of important stand recruitment to lag large fire activity events as revealed by the statistical reconstruction.) The correlation coefficients analysis over the interval 1790-1970 (Fig. 7a) indicated that the stand age distribution lagged the statistical reconstruction of 
the area burned by $4-9$ years $(r=0.56[0.18 ; 0.78]$ in the 8 -year lag; $n=19$ ). The correlation coefficients were below the satisfactory significance level when the 1780s-1990s period was analysed $(r=0.39[-0.02 ; 0.72] ; n=22)$. A visual inspection of decadal sums revealed a good fit between the time series from the early 19th to late 20th centuries (Fig. $7 b$ ).

Verification was made to find if a better fit could be obtained using a predictive model calibrated on fire statistics from an aggregate of ecoregions closest to the study area (not shown). In this procedure, fire occurrence statistics from ecoregions 94, 96, 97, and 99 were calibrated on the leading principal component of the $\mathrm{APw}, \mathrm{APe}$, and SL reconstructions (calibration model $R^{2}=22.5 \%$ and adj. $R^{2}=18.3 \%$; $\mathrm{RE}<0$; model equation: $Y_{\mathrm{LOG} j}=0.88+0.09 \mathrm{PC}_{j-1}+0.10 \mathrm{PC}_{j}$ ). Correlation analysis indicated that a better fit between stand age departures and predicted fire occurrence could not be obtained over the interval 1790s-1970s ( $r=0.60[0.16 ; 0.84]$ in the 8 year lag; $n=19)$. But better results were obtained over the interval 1780s-1990s $(r=0.49$ [0.04; 0.76]; $n=22)$ (Appendix 1, Fig. A2). The occurrence rates estimation of extreme events yielded results qualitatively similar to Fig. $5 a$ (Appendix 1, Fig. A2).

A correlation analysis (not shown) was also made between ranked stand age departures and ranked 10-year non-overlapping averages of the APe CDC reconstruction (Fig. 2e). This analysis did not yield better results $(r=0.39$ [-0.08; 0.70]; interval 1780s-1990s; $n=22$ ).

\section{Discussion}

\section{Statistical reconstruction of the fire activity}

The results from the present work showed that the dendrochronological reconstructions of the summer drought explained a significant portion of the variance in the annual area burned and fire occurrence on the Boreal Shield. This relation indicated that a strong summer drought signal was linking fire activity (Flannigan and Harrington 1988; Skinner et al. 1999, 2002) and tree radial growth (Hofgaard et al. 1999; Tardif et al. 2002; Girardin and Tardif 2005; Girardin et al. 2006). This covariance is not surprising as both trees and fires, at large spatial units, respond to similar synoptic scale environmental delivery factors, that is, the presence of upper atmospheric ridges and troughs upstream or above the study area (Skinner et al. 1999; Girardin et al. 2004a; Girardin and Tardif 2005).

Fire activity across the Boreal Shield is known for being highly variable in the space dimension (Harrington 1982). Greatest fire occurrence and area burned occur in the boreal region of west-central Canada (Stocks et al. 2003; see Fig. 1). This is due to a combination of fire-prone ecosystems, extreme fire-weather (a continental climate), frequent lightning activity, and reduced levels of protection in the region (Stocks et al. 2003). Despite the good predictive skills of the calibration models for predicting fire activity on the Boreal Shield, caution is required in regard to the interpretation of the results. The regression coefficients $\beta_{1}$ and $\beta_{2}$ retained by the stepwise regression models (Eqns 4 and 5) are representative of a large atmospheric circulation field located over Hudson Bay (Girardin et al. 2006). This circulation affects climate more or less in the east-central portion of the Boreal Shield (Girardin et al. 2004a, 2006). In contrast, most of the area burned in the west-central Canada region, that is where the statistical reconstructions appear as non-representative of fire variability (Fig. 3), are due to anomalous ridging over Saskatchewan, Manitoba, and western Ontario.

Therefore, the statistical reconstructions of the fire activity are missing some of the information that is regional in scale, especially in the west-east dimension. Trials to reconstruct fire activity in this west-east dimension, i.e. at the scale of ecoregions or by splitting the Boreal Shield into western and eastern sectors, have so far been unsuccessful, likely because of the low spatial coverage of the predictors. An extension of the drought reconstruction network across the Boreal Shield could solve the west-east dimension issue. Also, the statistical reconstructions have limitations in regard to their use as a proxy of long-term changes in the average fire activity. Tree-ring records on the Boreal Shield, with few exceptions, are relatively short (see Girardin et al. 2006). There cannot allow robust reconstruction of low frequency variations in actual data. The statistical reconstructions of the fire activity nonetheless can contribute to increasing our understanding of natural patterns of year-to-year and decade-to-decade fire variability on a large portion of the Boreal Shield.

An alternative to some of these issues would be to use carefully selected multicentury tree-ring chronologies as predictors of fire activity (Larsen 1996; Girardin et al. in press). The potential of tree-rings for predicting fire activity has been reported in other locations of the boreal forest. In Northern Alberta, Larsen (1996) found that 56\% of the variance in area burned in Wood Buffalo National Park could be accounted for by variance in radial growth. Larsen and MacDonald (1995) suggested that high correlation between tree radial growth and area burned reflects the fact that both processes are sensitive to summer dryness and seasonal distribution of precipitation. The authors suggested that tree-rings could be used as proxy for regional fire activity. In east European Russia, Drobyshev and Niklasson (2004) suggested that it was possible to define an indirect relationship between variance in tree-rings and data of fire activity. A total of $40 \%$ of the variance in area burned in the Komi Republic during 1950-1990 could be accounted for by regional minimum, maximum, earlywood, and latewood density chronologies. Some of our analyses indicated that an indirect relationship between variance in tree-ring chronologies and fire data could effectively be used to estimate past fire activity for the Boreal Shield. However, many of the chronologies were developed in the 1980s and early 1990s (see Girardin et al. 2006) and thus 
constrain the calibration models to be conducted on fewer observations.

\section{Comparison with the stand age distribution}

The comparison between the stand age distribution and the statistical reconstruction of the area burned was one in which a large spatial unit was compared to a finer one. It is recognized that large spatial units (ecozone level) provide better results when linking fire activity to climate factors (Amiro et al. 2004; Flannigan et al. 2005). Fire is highly variable among years and the use of a large number of samples provides some statistical smoothing. Despite differences in scale, strong coherence was apparent from $c .1830$ s to 1980 s. Other than differences in scaling, inconsistencies between the statistical reconstruction of the area burned and the stand age distribution (prior to the 1830s and after the 1970s) are likely associated with the determination of the time-since-last-fire, the influence of human activities on regional fire regimes, or due to regional fire events.

Intriguingly, the long-term trend observed in the stand age distribution (i.e. peaks in the $1820 \mathrm{~s}-1830$ s and $1910 \mathrm{~s}-$ $1920 \mathrm{~s}$, and troughs in the $1860 \mathrm{~s}-1880 \mathrm{~s}$ and $1950 \mathrm{~s}-1960 \mathrm{~s}$ ) were concordant with changes in occurrence rates of extreme fire years. These trends were present in the dendroclimatic drought reconstructions of Girardin et al. (2006) in spite of the removal of low frequencies from the tree-ring data. Perhaps this may indicate that the stand age distributions are not solely a function of the average fire activity but a function of the interval between periods of clustered extreme fire years. This finding may stress the importance of considering the occurrence rate of extreme fire years in the forecasting tools used to predict climate change impacts on Canadian boreal forests' 'natural fire regimes'. Most often, forecasting tools applied to these forests strictly focus on aspects related to the average fire activity (Bergeron et al. 2004a; Flannigan et al. 2005).

Even though weather and climate are the most important factors in fire activity, other factors such as fire suppression, land use, ignition sources, and fuel can influence fire statistics (Podur et al. 2002). The combination of all these factors can make the identification of trends in fire statistics and the study of their drivers difficult. In this regard, fire activity proxies, such as derived from post-fire stand initiation maps or from tree-rings, can provide valuable inputs. For example, many of the Abitibi Plains fires in the 1910s-1920s started during intensive European colonisation (Lefort et al. 2003; Bergeron et al. 2004b). Since 1920, large fires in the southwestern Quebec boreal forest were mainly concentrated in the more populated area whereas few fires were observed in the virgin coniferous forest (Bergeron et al. 2004b). According to Girardin et al. $(2004 a, 2004 b)$, however, the 1910s-1920s fires also occurred at a time when the climate in the Abitibi Plains was very conducive to fire (see also Lefort et al. 2003). The peak in forest fire activity was also observed in adjacent landscapes where pristine forest dominated (Lefort et al. 2003; Bergeron et al. 2004b), suggesting climate was a major influence. The statistical reconstructions of the fire activity did suggest the 1910s as the most important decade of fire activity during the past 200 years or so. The kernel estimation also suggested a high occurrence rate of extreme fire activity events during the early 20th century. The stand age distribution shows the 1910s-1920s as the most extreme decades of fire activity. In this example, the fire proxies corroborate each other by showing that greater fire activity occurred through the first half of the 20th century and lower fire activity through the second half.

\section{Concluding remarks}

Statistical reconstructions of the fire activity provide insights on inter-annual- to decadal-scale fire variability at times during which there were no modern documentary records (Westerling and Swetnam 2003). As opposed to documentary fire records from recent decades, the long-term information provided by tree-ring width statistical reconstructions is relatively uninfluenced by human intervention and by ongoing changes in management policies and expansion of fire detection. Consequently, the statistical reconstructions of the fire activity may provide valuable insights on the long-term behaviour of the 'natural fire regimes'. These data can notably help us to place recent changes in fire activity within the long-term history of the forests. Most importantly, statistical reconstructions of the fire activity provide quantitative means for measuring the control of climate on fire activity (Bergeron and Archambault 1993; Westerling and Swetnam 2003).

\section{Acknowledgements}

We acknowledge the Sustainable Forest Management Network (SFMN) for funding this research and supporting M. P. Girardin. The author was also supported by scholarships from the Fonds Québécois de la Recherche sur la Nature et les Technologies (FQRNT) and the Prairies Adaptation Research Collaborative (PARC). We thank the two anonymous reviewers and the associate editor for providing helpful comments on an earlier version of the manuscript.

\section{References}

Amiro BD, Logan KA, Wotton BM, Flannigan DM, Todd JB, Stocks BJ, Martell DL (2004) Fire weather index system components for large fires in the Canadian boreal forest. International Journal of Wildland Fire 13, 391-400. doi:10.1071/WF03066

Baskerville GL (1971) Use of logarithmic regression in the estimation of plant biomass. Canadian Journal of Forest Research 2, 49-53.

Bergeron Y, Archambault S (1993) Decreasing frequency of forest fires in the southern boreal zone of Quebec and its relation to global warming since the end of the 'Little Ice Age'. The Holocene $\mathbf{3}$, 255-259.

Bergeron Y, Gauthier S, Kafka V, Lefort P, Lesieur D (2001) Natural fire frequency for the eastern Canadian boreal forest: consequences for sustainable forestry. Canadian Journal of Forest Research 31, 384-391. doi:10.1139/CJFR-31-3-384 
Bergeron Y, Flannigan M, Gauthier S, Leduc A, Lefort P (2004a) Past, current and future fire frequency in the Canadian boreal forest: implications for sustainable forest management. Ambio 33, 356-360.

Bergeron Y, Gauthier S, Flannigan M, Kafka V (2004b) Fire regimes at the transition between mixedwoods and coniferous boreal forest in northwestern Quebec. Ecology 85, 1916-1932.

Bessie WC, Johnson EA (1995) The relative importance of fuels and weather on fire behavior in subalpine forests in the southern Canadian Rockies. Ecology 26, 747-762.

Bonan G (2002) 'Ecological climatology.' (Cambridge University Press: New York)

Cook ER, Kairiukstis LA (1990) 'Methods of dendrochronology. Applications in the environmental sciences.' (Kluwer Academic Publishers: Boston)

Cook ER, Briffa KR, Jones PD (1994) Spatial regression methods in dendroclimatology: a review and comparison of two techniques. International Journal of Climatology 14, 379-402.

Cook ER, D'Arrigo RD, Mann ME (2002) A well-verified, multiproxy reconstruction of the winter North Atlantic Oscillation index since AD 1400. Journal of Climate 15, 1755-1764. doi:10.1175/15200442(2002)015<1754:AWVMRO > 2.0.CO;2

Cox DR, Lewis PAW (1966) 'The statistical analysis of series of events.' (John Wiley \& Sons: New York)

DesRochers A, Gagnon R (1997) Is ring count at ground level a good estimation of black spruce age? Canadian Journal of Forest Research 27, 1263-1267. doi:10.1139/CJFR-27-8-1263

Drobyshev I, Niklasson M (2004) Linking tree-rings, summer aridity, and regional fire data: an example from the boreal forests of the Komi Republic, east European Russia. Canadian Journal of Forest Research 34, 2327-2339. doi:10.1139/X04-112

Ecological Stratification Working Group (1996) 'A national ecological framework for Canada.' (Agriculture and Agri-Food Canada and Environment Canada: Ottawa, ON)

Environment Canada (2002) 'Canadian climate normals 1971-2000.' (Canadian Climate Program, Environment Canada, Atmospheric Environment Service: Downsview, ON)

Flannigan MD, Harrington JB (1988) A study of the relation of meteorological variables to monthly provincial area burned by wildfire in Canada (1953-80). Journal of Applied Meteorology 27, 441-452. doi:10.1175/1520-0450(1988)027<0441:ASOTRO>2.0.CO;2

Flannigan MD, Logan KA, Amiro BD, Skinner WR, Stocks BJ (2005) Future area burned in Canada. Climatic Change 72, 1-16. doi: $10.1007 / \mathrm{S} 10584-005-5935-Y$

Folland CK, Karl TR, Christy JR, Clarke RA, Gruza GV, Jouzel J, Mann ME, Oerlemans J, Salinger MJ, Wang SW (2001) Observed climate variability and change. In 'Climate change 2001: the scientific basis'. (Eds JT Houghton, Y Ding, DJ Griggs, M Noguer, PJ van der Linden, X Dai, K Maskell, CA Johnson) pp. 99-181. (Cambridge University Press: New York)

Fox JF (1989) Bias in estimating forest disturbance rates and tree lifetimes. Ecology 70, 1267-1272.

Girardin MP, Tardif J (2005) Sensitivity of tree growth to the atmospheric vertical profile in the Boreal Plains of Manitoba. Canadian Journal of Forest Research 35, 48-64. doi:10.1139/X04-144

Girardin MP, Tardif J, Bergeron Y (2002) Dynamics of eastern larch stands and its relationships with larch sawfly outbreaks in the Northern Clay Belt of Quebec. Canadian Journal of Forest Research 32 , 206-216. doi:10.1139/X01-185

Girardin MP, Tardif J, Flannigan MD, Wotton BM, Bergeron Y (2004a) Trends and periodicities in the Canadian Drought Code and their relationships with atmospheric circulation for the southern Canadian boreal forest. Canadian Journal of Forest Research 34, 103-119. doi:10.1139/X03-195
Girardin MP, Tardif J, Flannigan MD, Bergeron Y (2004b) Multicentury reconstruction of the Canadian Drought Code from eastern Canada and its relationship with paleoclimatic indices of atmospheric circulation. Climate Dynamics 23, 99-115. doi:10.1007/S00382-0040417-X

Girardin MP, Tardif JC, Flannigan MD, Bergeron Y (2006) Synoptic scale atmospheric circulation and boreal Canada summer drought variability of the past three centuries. Journal of Climate 19, 19221947. doi:10.1175/JCLI3716.1

Girardin MP, Tardif J, Flannigan MD (in press) Temporal variability in area burned for the Province of Ontario, Canada during the past 200 years inferred from tree rings. Journal of Geophysical Research.

Gutsell SL, Johnson EA (2002) Accurately ageing trees and examining their height-growth rates: implication for interpreting forest dynamics. Journal of Ecology 90, 153-166. doi:10.1046/J.00220477.2001.00646.X

Harrington JB (1982) 'A statistical study of area burned by wildfire in Canada 1953-1980.' Canadian Forest Service, Petawawa National Forest Institute, Information Report PI-X-16. (Petawawa, ON)

Hofgaard A, Tardif J, Bergeron Y (1999) Dendroclimatic response of Picea mariana and Pinus banksiana along a latitudinal gradient in the eastern Canadian boreal forest. Canadian Journal of Forest Research 29, 1333-1346. doi:10.1139/CJFR-29-9-1333

Holmes RL (1999) 'Dendrochronology program library and the dendroecology program library.' (Laboratory of Tree-Ring Research, University of Arizona: Tucson, AZ)

Houghton JT, Ding Y, Griggs DJ, Noguer M, van der Linden PJ, Xiaosu D, Maskell K, Johnson CA (2001) 'Climatic change, 2001: The scientific basis. Contribution of working group I to the third assessment report of the intergovernmental panel on climate change.' (Cambridge University Press: Cambridge, UK)

Johnson EA (1992) 'Fire and vegetation dynamics: studies from the North American boreal forest.' (Cambridge University Press: Cambridge, UK)

Johnson EA, Gutsell SL (1994) Fire frequency models, methods and interpretations. Advances in Ecological Research 25, 239-287.

Johnson EA, Larsen CPS (1991) Climatically induced change in fire frequency in the southern Canadian Rockies. Ecology $\mathbf{7 2}$ 194-201.

Johnson EA, Wowchuk DR (1993) Wildfires in the southern Canadian Rockies and their relationship to mid-tropospheric anomalies. Canadian Journal of Forest Research 23, 1213-1222.

Kneeshaw DD, Claveau Y (2001) Comment - Effects of adventitious roots on age determination in balsam fir regeneration. Canadian Journal of Forest Research 31, 1292-1295. doi:10.1139/CJFR-317-1292

Larsen CPS (1996) Fire and climate dynamics in the boreal forest of northern Alberta, Canada, from AD 1850 to 1989. The Holocene 6 , $449-456$

Larsen CPS (1997) Spatial and temporal variations in boreal forest fire frequency in northern Alberta. Journal of Biogeography $\mathbf{2 4}$ 663-673.

Larsen CPS, MacDonald GM (1995) Relations between tree-ring widths, climate, and annual area burned in the boreal forest of Alberta. Canadian Journal of Forest Research 25, 1746-1755.

Lefort P, Gauthier S, Bergeron Y (2003) The influence of fire weather and land use on the fire activity of the Lake Abitibi area, eastern Canada. Forest Science 49, 509-521.

Legendre P, Legendre L (1998) 'Numerical ecology.' (Elsevier: New York)

Linsley RK, Kohler MA, Paulhus JL (1982) 'Hydrology for engineers.' 3rd edn. (McGraw-Hill: New York)

Luterbacher J, Xoplaki E, Dietrich D, Rickli R, Jacobeit J, Beck C, Gyalistras D, Schmutz C, Wanner H (2002) Reconstruction of sea 
level pressure fields over the Eastern North Atlantic and Europe back to 1500 . Climate Dynamics 18, 545-561.

Masters AM (1990) Changes in forest fire frequency in Kooteney National Park (British Columbia, Canada), Canadian Rockies. Canadian Journal of Botany 68, 1763-1767.

Mudelsee M (2002) XTREND: A computer program for estimating trends in the occurrence rate of extreme weather and climate events. In 'Scientific reports, no. 26'. (Eds A Raabe, K Arnold) pp. 149195. (Institute of Meteorology, Institute for Tropospheric Research, University of Leipzig: Leipzig)

Mudelsee M (2003) Estimating Pearson's correlation coefficient with bootstrap confidence interval from serially dependent time series. Mathematical Geology 35, 651-665. doi:10.1023/B:MATG. 0000002982.52104 .02

Mudelsee M (2006) CLIM-X-DETECT: A Fortran 90 program for robust detection of extremes against a time-dependent background in climate records. Computers and Geosciences 32, 141-144.

Mudelsee M, Börngen M, Tetzlaff G, Grünewald U (2003) No upward trends in the occurrence of extreme floods in central Europe. Nature 425, 166-169. doi:10.1038/NATURE01928

Mudelsee M, Börngen M, Tetzlaff G, Grünewald U (2004) Extreme floods in central Europe over the past 500 years: Role of cyclone pathway "Zugstrasse Vb". Journal of Geophysical Research 109(D23), D23101. doi:10.1029/2004JD005034

Nash CH, Johnson EA (1996) Synaptic climatology of lightning-caused forest fires in subalpine and boreal forests. Canadian Journal of Forest Research 26, 1859-1874.

Newark MJ (1975) The relationship between forest fire occurrence and $500 \mathrm{mb}$ longwave ridging. Atmosphere 13, 26-33.

Podur J, Martell DL, Knight K (2002) Statistical quality control analysis of forest fire activity in Canada. Canadian Journal of Forest Research 32, 195-205. doi:10.1139/X01-183

Robitaille A, Saucier JP (1998) 'Paysages régionaux du Québec méridional.' (Les Publications du Québec: Sainte-Foy, QC)

SAS Institute (1990) 'SAS/STAT user's guide. Version 6.' 4th edn. (SAS Institute: Cary, $\mathrm{NC}$ )

Skinner WR, Stocks BJ, Martell DL, Bonsal B, Shabbar A (1999) The association between circulation anomalies in the mid-troposphere and the area burned by wildland fire in Canada. Theoretical and Applied Climatology 63, 89-105. doi:10.1007/S007040050095

Skinner WR, Flannigan MD, Stocks BJ, Martell DL, Wotton BW, Todd JB, Mason JA, Logan KA, Bosch EM (2002) A 500-hPa synoptic wildland fire climatology for large Canadian forest fires, 1959-1996. Theoretical and Applied Climatology 71, 157-169. doi: $10.1007 / \mathrm{S} 007040200002$

Stocks BJ, Mason JA, Todd JB, Bosch EM, Wotton BM, et al. (2003) Large forest fires in Canada, 1959-1997. Journal of Geophysical Research (D Atmos.) 108, 8149. doi:10.1029/2001JD000484

Swetnam T (1993) Fire history and climate change in giant sequoia groves. Science 262, 885-889.

SYSTAT (1998) 'SYSTAT Version 9.1 software.' (SPSS: Chicago)

Tardif J (2004) 'Fire history in the Duck Mountain Provincial Forest, western Manitoba.' Sustainable Forest Management Network, Project Reports 2003/2004 series. (University of Alberta: Edmonton, $\mathrm{AB}$ )

Tardif J, Conciatori F, Bergeron Y (2002) Comparative analysis of the climatic response of seven boreal tree species from north-western Québec, Canada. Tree-Ring Research 57, 25-37.

Ter Braak CJF, Smilauer P (1998) 'Canoco reference manual and users' guide to Canoco for windows: software for canonical community ordination version 4.' (Microcomputer Power: Ithaca, New York)

Turner JA (1972) 'The drought code component of the Canadian Forest Fire Behaviour System.' Environment Canada, Canadian Forest Service Publication 1316. (Ottawa, ON)

Van Wagner CE (1987) 'Development and structure of the Canadian Forest Fire Weather Index System.' Canadian Forest Service, Forestry Technical Report 35. (Ottawa, ON)

Veillette JJ (1994) Evolution and paleohydrology of glacial lakes Barlow and Ojibway. Quaternary Science Reviews 13, 945-971. doi:10.1016/0277-3791(94)90010-8

Westerling AL, Swetnam TW (2003) Interannual to decadal drought in the Western United States. EOS, Transactions, American Geophysical Union 84, 545-560.

Wong CM, Lertzman KP (2001) Errors in estimating tree age: implications for studies of stand dynamics. Canadian Journal of Forest Research 31, 1262-1271. doi:10.1139/CJFR-31-7-1262

Zar JH (1999) 'Biostatistical analysis.' 4th edn. (Prentice Hall: NJ)

Zhang X, Vincent L, Hogg WD, Niitsoo A (2000) Temperature and precipitation trends in Canada during the 20th century. Atmosphere and Ocean 38, 395-429. 


\section{Appendix 1}

The following descriptions of the reduction of error and product means test statistics were taken from Cook and Kairiukstis (1990). The equation used to calculate the RE can be expressed in terms of the $\hat{y}_{i}$ estimates and $y_{i}$ predictand that are expressed as departures from the dependent period mean value:

$$
\mathrm{RE}=1.0-\sum_{i=1}^{n^{\prime}}\left(y_{i}-\hat{y}_{i}\right)^{2} / \sum_{i=1}^{n^{\prime}} y_{i}^{2} .
$$

The term to the right of Eqn 6 is the ratio of the total squared error obtained with the regression estimates and the total squared error obtained using the dependent period mean as the only estimate. This average becomes a standard against which the regression estimation is compared. If the reconstruction does a better job than the average of the dependant period, then the total error of the regression estimate is less, the ratio is less than one, and the $\mathrm{RE}$ is positive.

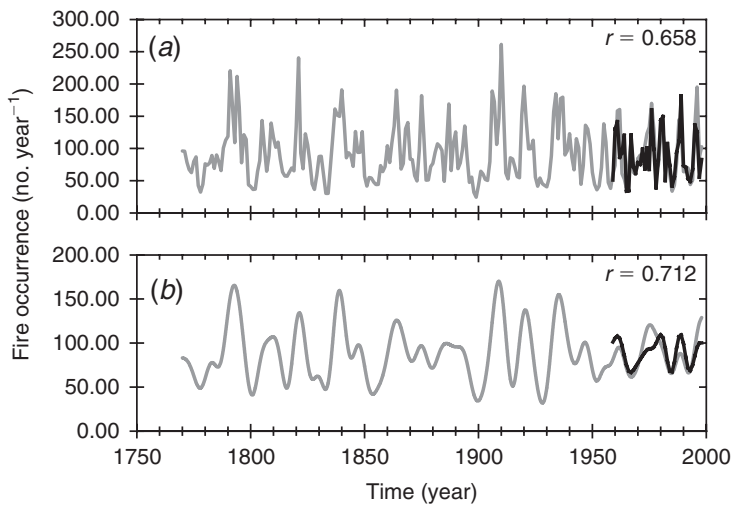

Fig. A1. (a) Boreal Shield statistical reconstruction of the fire occurrence (number of fires of size $>200$ ha; period 1770-1998) against the instrumental fire record (bold line, period 1959-1998). Variance in the instrumental fire record was adjusted to correspond to the reconstruction. (b) Ten-year window polynomial curve (order 8) of reconstructed and instrumental fire occurrence. The Spearman correlation coefficient between the two time series for their common interval is indicated $(n=40)$.
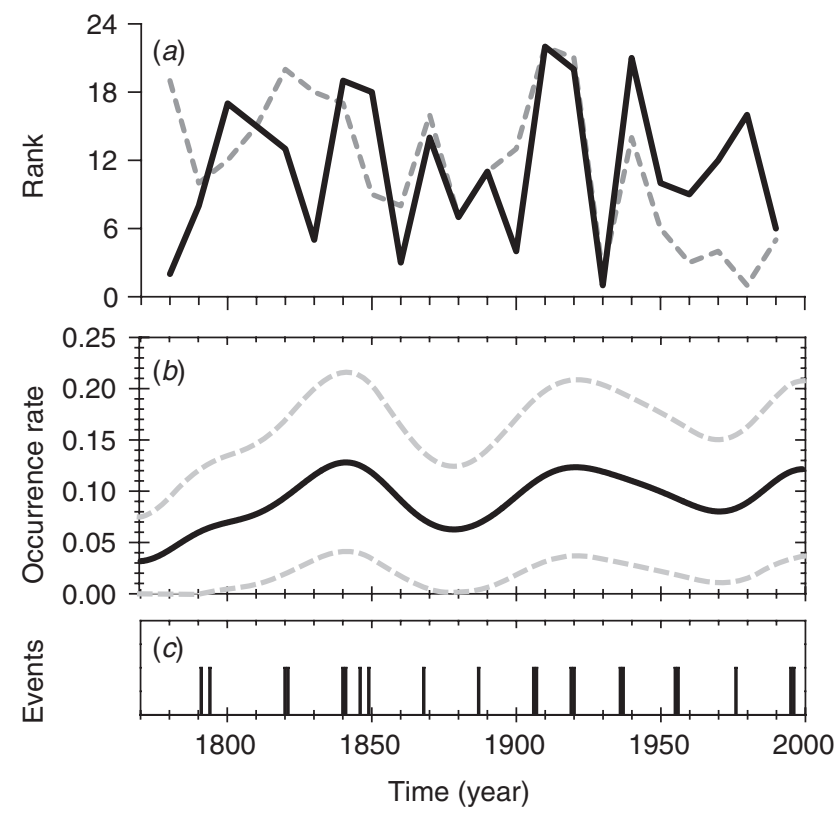

Fig. A2. (a) Ranked departures from the exponential fit to the stand age distribution (dashed line) against ranked decadal sums of predicted fire occurrence for an aggregate of ecoregions corresponding to -8year lag (solid line). (b) Occurrence rate of $(c)$ extreme fire occurrence events $(n=21)$. Refer to Fig. 5 for parameter values and definitions.

The PM test calculates the products of the deviations and collects the positive and negative products in two separate groups based on their sign. The values of the products in each group are summed, and the means computed. The difference between the absolute values of the two means $\mathrm{M}_{+}-M_{-}$can be tested for significance using the $t$ statistics:

$$
t=\left(M_{+}-M_{-}\right) /\left(S_{+}^{2} / n_{+}+S_{-}^{2} / n_{-}\right)^{1 / 2},
$$

where $n_{+}$and $n_{-}$are the number of positive and negative products and $S_{+}^{2}$ and $S_{-}^{2}$ are the corresponding variance. 